\title{
Desafios colocados para a clínica psicanalítica (e seu futuro) no contexto da pandemia de COVID-19. Reflexões a partir de uma experiência clínica
}

\section{Challenges posed to the psychoanalytic clinic (and its future) in the context of the COVID-19 pandemic: reflections on clinical experience}

Francisco Capoulade*1 Mário Eduardo Costa Pereira *2

O objetivo deste trabalho é apresentar a implementação de um serviço de atendimento psicanalítico com suporte virtual no contexto nascente da pandemia de COVID-19 e as questões que dessa experiência surgiram, em especial o papel dos corpos e das tecnologias de comunicação na iniciação, manutenção e do final da análise.

Palavras-chave: Clínica psicanalítica, atendimento online, pandemia, COVID-19

*1 Instituto de Pesquisa e Estudos em Psicanálise nos Espaços Públicos - IPEP (Campinas, SP, Brasil).

*2 Universidade Estadual de Campinas - Unicamp (Campinas, SP, Brasil). 


\section{Introdução}

Há tempos se discute, no campo psicanalítico, a respeito da utilização de novas tecnologias na clínica. Não raro é encontrarmos artigos (Caffé, Rocha \& Pereira, 2007), livros e comunicações em congressos que tratam desse assunto. Pode-se afirmar que esse tema vem sendo abordado com certa constância e com um número crescente de interessados há pelo menos duas décadas. Não é algo novo, nem mesmo desconhecido para a grande maioria dos clínicos. Assim sendo, é possível encontrar tanto entusiastas dessas tecnologias, como uma significativa parcela daqueles que delas desconfiam.

Desde o uso do telefone fixo até as plataformas de videoconferências, passando, é claro, pelos smartphones, essas tecnologias das comunicações vinham sendo utilizadas com certa frequência por psicanalistas. Já era comum ouvirmos colegas relatando ca- sos de dois ou três pacientes que atendiam online, ou mesmo aqueles psicanalistas que foram estudar/trabalhar fora do Brasil e por um período determinado atenderam seus analisantes utilizando-se desses instrumentos. Ou seja, pensávamos que tínhamos certa experiência com relação à utilização dessas ferramentas. Parecia ser algo que aos poucos penetrava o campo clínico (Migone, 2013; Scharff, 2017). Mas bem aos poucos. Havia uma hesitação em pontos muito importantes como, por exemplo, receber novos pacientes, clínica com crianças, trabalhos clínicos com psicóticos, tratamento de pacientes com risco iminente de suicídio etc. Tais situações podiam contribuir para que não se aderisse a essas tecnologias de modo mais amplo, já que havia um risco considerável. Não obstante, tais riscos não estariam também colocados em uma situação presencial? Qual seria a diferença fundamental aí? Voltaremos a esse tema.

Pois bem, se ao final de 2019, ou mesmo no início de 2020, alguém nos perguntasse sobre a utilização dessas novas tecnologias na clínica psicanalítica, provavelmente responderíamos que se tratava de uma realidade que estava à nossa disposição e que a transmissão dessas experiências analíticas vinham sendo realizadas 
com certa frequência e com um número relativamente grande de adeptos e simpatizantes, ainda que com suas precauções. Mas que ainda precisaríamos de um tempo para compreender seu funcionamento e seus efeitos tanto em nossas vidas como na clínica psicanalítica propriamente dita.

Contudo, a fragilidade de nossa realidade deu notícias. E as deu de maneira imperiosa. Eis que um vírus com um significativo grau de letalidade, chamado a posteriori de SARS-CoV-2 (causador da COVID-19), foi identificado na China em novembro de 2019 (até o presente momento essas são as informações oficiais) e muda radicalmente o curso das atividades humanas, tanto no Oriente como no Ocidente. Na clínica psicanalítica não foi diferente. Os efeitos foram sentidos de maneira quase imediata. Aqui no Brasil, enquanto acompanhávamos os acontecimentos na China e na Europa, preparávamo-nos como se uma guerra estivesse por eclodir. $\mathrm{O}$ discurso científico nos lançou em uma realidade completamente nova para essa geração. Rapidamente, a necessidade sanitária de isolamento social nos colocou dentro de nossas casas e apartamentos - aqueles que tinham essa possibilidade, vale lembrar. Em menos de um mês quase a totalidade dos psicanalistas estava atendendo online. Os consultórios foram "abandonados".

536 Migramos rapidamente para os celulares e computadores, agora nossos novos consultórios. Ganhamos algumas horas, relativas aos deslocamentos, todavia, perdemos algumas fronteiras. Os espaços passaram a se confundir. Uma outra realidade se impôs abruptamente. Houve um momento disruptivo provocando um antes e um depois. Então, o que ontem suscitava hesitações e posições controversas, hoje passava a ser a única possibilidade segura do ponto de vista sanitário para o desenvolvimento da clínica.

Diga-se de passagem, isso não foi um fenômeno particular da psicanálise. As clínicas médicas, por exemplo, tiveram que se reenquadrar depressa e cumprir novas exigências. O Conselho Federal de Medicina autorizou o teleatendimento durante a pandemia, ainda que já houvesse uma resolução de 2018 permitindo tal prática.

De um só golpe fomos lançados em duplo movimento. Por um lado, uma aceleração da experiência tecnológica, provocando um debate urgente sobre questões acerca do setting analítico, mas muito mais que um debate, estimulando uma prática clínica em uma nova plataforma de modo massivo. Por outro lado, a necessidade de lidar com a fragilidade de nossas convenções. Nossas seguranças e certezas neuróticas foram abaladas.

No que diz respeito à clínica psicanalítica, alguns psicanalistas surgiram em suas redes sociais com lives. Essa forma de comunicação, muito comum 
nas redes sociais, era pouco utilizada por psicanalistas. Mesmo os que têm grande número de seguidores em suas redes como Vera Iaconelli, Contardo Calligaris, Christian Dunker e Maria Homem (para citar alguns) não tinham o hábito de realizar lives. Um dos primeiros a se utilizar desse recurso foi Antonio Quinet. Ao mesmo tempo em que procurava transmitir suas impressões mais recentes desse trabalho clínico, também se esforçava por teorizar a partir da clínica psicanalítica. Pouco a pouco, outros psicanalistas foram se juntando ao esforço de Quinet, procurando transmitir suas próprias experiências nesse formato. Em pouco tempo, tal qual a velocidade de transmissão do vírus SARS-CoV-2, as lives se espalharam. Associações, escolas e institutos de psicanálise, além, é claro, da iniciativa de cada um, começaram a promover debates ao vivo na internet. Um grande público de psicanalistas de diversas orientações começou a se formar.

À primeira vista, é possível perceber as diferenças de um atendimento presencial (setting tradicional) e atendimento online. Mas é disso que se trata? São apenas diferenças de lugares? De plataformas? Acreditamos que o tema é mais complexo e que é preciso um esforço maior de nossa parte para respondermos a essa questão.

Ao longo de todo o movimento psicanalítico, observamos diversas experiências clínicas nas quais o setting não foi o promovedor e tampouco o garantidor de uma experiência psicanalítica. Desde os trabalhos de Sándor Ferenczi na década de 1910 (Alves Lima, 2019) até os trabalhos clínicos empreendido por psicanalistas que estão no serviço público brasileiro (SUS) (Figueiredo, 1997), passando pelas clínicas públicas que se multiplicaram pela Europa na década de 1920 (Danto, 2019), pela clínica social de Hélio Pelegrino no fim década de 1960 e também por atendimentos em praças de diversos municípios do Brasil (Ab’Sáber \& Broide, 2017; Coaracy \& Guimarães, 2017), podemos encontrar iniciativas promissoras e com efeitos importantes.

Essas iniciativas tiveram um êxito reconhecido por grande parte da comunidade psicanalítica. Não obstante, podemos recolocar a questão. Não nos parece que se trata de discutir acerca do setting tradicional em oposição a dispositivos inventivos e fecundos, como as clínicas públicas. Mas quais as implicações entre a presença e a virtualidade na clínica psicanalítica? Ou seja, a ausência dos corpos seria algo que impossibilitasse a experiência analítica? $\mathrm{E}$, por que não?, quais as eventuais consequências para o futuro das práticas psicanalíticas, agora colocadas ao alcance de um público muito mais amplo e economicamente vulnerável, através dos atendimentos online?

Para tentar avançar um pouco mais nessa direção, gostaríamos de apresentar um recente trabalho desenvolvido por nós na cidade de Campinas 
(ainda que de partida as fronteiras geográficas já tenham sido borradas) com o intuito de pensar as experiências clínicas online no começo da pandemia.

Diante da urgência que o momento solicitava, coletivos de psicanalistas foram se formando com o intuito de oferecer escuta aos profissionais da saúde que estavam na linha de frente do combate à COVID-19. No caso do Brasil, é possível observar tal organização em praticamente todos os Estados. Em Campinas organizamos um coletivo de psicanalistas a partir da iniciativa do Instituto de Pesquisa e Estudos em Psicanálise nos Espaços Públicos (IPEP) e do Laboratório de Psicopatologia Sujeito e Singularidade (LaPSuS) da Universidade Estadual de Campinas (Unicamp).

\section{A construção de um serviço de atendimento psicanalítico com suporte virtual}

Ainda no mês de março de 2020, quando as notícias vindas da Itália, em especial da região da Lombardia, nos aterrorizavam, e quando os casos de contaminação no Brasil começaram a ser identificados, as duas instituições (IPEP e LaPSUS) se uniram com o propósito de organizar um serviço de escuta online para os profissionais da saúde. Vivíamos um ambiente cheio de incertezas e perigo de morte real. Das poucas certezas que tínhamos, uma delas era que em poucas semanas nossos hospitais estariam lotados de pacientes acometidos pelo novo coronavírus e que os profissionais da saúde precisariam de algum tipo de escuta. Afinal eram os que mais estavam expostos ao perigo.

Em duas semanas, conseguimos montar um dispositivo com mais de cinquenta psicanalistas. A maioria estava na cidade de Campinas, mas também participaram psicanalistas das cidades de Jundiaí, Itatiba, Indaiatuba, Valinhos, São Paulo, entre outras cidades. Parte dos psicanalistas participantes integrava algum tipo de instituição de psicanálise (em geral, de orientação lacaniana), outra parte não estava filiada a nenhuma instituição de psicanálise. $\mathrm{O}$ grupo que se criou era heterogêneo e muitos nem se conheciam.

No dia 30 de março, havíamos criado um grupo no WhatsApp, aplicativo pelo qual começamos nossas comunicações. No dia 5 de abril às $21 \mathrm{~h}$, realizamos nossa primeira reunião com todos os envolvidos. Nessa reunião, apresentamos aos envolvidos os principais pontos que imaginávamos serem necessários para o funcionamento do serviço de atendimento online. Em grande medida, muito do que foi apresentado era resultado das experiências 


\section{ARTIGOS}

precedentes de práticas de atendimentos de orientação psicanalítica em serviço hospitalar público e universitário, anteriormente adquiridas com o serviço de psicoterapia psicanalítica sustentado pelo então Laboratório de Psicopatologia Fundamental da Unicamp.

\section{Funcionamento de serviço}

Após apresentação e debate desses pontos, pudemos estabelecer os seguintes critérios para os atendimentos. 1) o atendimento seria individual, online e gratuito; 2) o atendimento teria a duração máxima de 3 meses (a partir do início da terapia); e 3) a frequência dos atendimentos seria decidida entre o(a) solicitante e o(a) psicanalista, assim como a tecnologia a ser utilizada, ou seja, a plataforma. Esses critérios, que funcionaram como uma espécie de diretrizes, foram amplamente divulgados nas redes sociais e no site do IPEP, bem como no do LaPSUS.

No que tange ao funcionamento interno do serviço, procedemos da seguinte maneira: criamos uma comissão de acolhimento que tinha como tarefa principal receber os solicitantes e encaminhá-los aos psicanalistas. Os solicitantes entravam em contato conosco única e exclusivamente pelo site do IPEP. Essa solicitação era encaminhada automaticamente para um dos participantes da comissão de acolhimento que entrava em contato com o solicitante para marcar uma entrevista. Após a realização dessa entrevista em que o(a) entrevistador(a) apresentava o funcionamento do serviço e escutava $o$ (a) solicitante, o(a) psicanalista, membro dessa comissão, encaminhava o(a) solicitante para atendimento. Isto feito, quem recebeu o encaminhamento entrava em contato com o(a) solicitante e marcava a primeira entrevista. Logo depois, o(a) psicanalista enviava um formulário para a comissão de acolhimento relatando o primeiro atendimento e depois encaminhava um pequeno relatório quando os atendimentos estivessem encerrados.

Em paralelo, criamos também um grupo dedicado à supervisão formado por oito psicanalistas mais experientes e que traziam na bagagem experiência de atendimento e supervisão no serviço público (SUS). A possibilidade da supervisão era a tentativa de garantir um mínimo de troca psicanalítica no cenário de incertezas que estávamos vivendo. E oficializar esse dispositivo pareceu o mais prudente a ser feito. Além disso, era também a possibilidade de contribuir para a formação de alguns que aderiram ao serviço e que se colocaram como analistas em formação. 
Ora, o funcionamento tinha regras básicas claras e com o propósito de garantir aos atendimentos uma performance impecável do ponto de vista sanitário, até mesmo do ponto de vista de determinada ética. Contudo, da perspectiva psicanalítica, o que essas regras e esses dispositivos poderiam assegurar? Em outras palavras, um serviço desse com tais regulações é suficiente para iniciar e sustentar uma análise?

\section{Possibilidades e limites da clínica psicanalítica online}

Antes de avançarmos, voltemo-nos para a seguinte questão: o que sustenta uma análise? Sem muita hesitação, poderíamos simplesmente dizer: a transferência e o desejo do analista. Mas isso não seria simplificar excessivamente a questão, em particular dadas as condições radicalmente novas impostas pelo atual contexto?

Para melhor tratar dessa questão, é necessário dizer das pretensões de nossos atendimentos. No caso do serviço que oferecemos, colocamo-nos de maneira mais modesta. Os atendimentos devem seguir os princípios básicos da psicanálise: escuta livre e atenção flutuante. $\mathrm{O}$ tratamento pretende oferecer escuta aos solicitantes diante da aflição que estão enfrentando no combate à COVID-19, ao mesmo tempo que pode possibilitar uma interrogação para além desse contexto, isto é, sobre o próprio sujeito. Em outras palavras, há que considerar os propósitos do dispositivo analítico ofertado sob a perspectiva daquilo que costumamos chamar de entrevistas preliminares em psicanálise, que funcionaria como referência do que se pode mobilizar no sujeito para além do acolhimento de sua angústia.

A experiência do IPEP/LaPSuS na constituição de uma rede de atendimentos psicanalíticos virtuais certamente não foi a única no contexto brasileiro. Ao contrário, um grande número de propostas de mesmo cunho começaram rapidamente a proliferar, tanto no âmbito de instituições psicanalíticas e universitárias, como no caso aqui descrito, como aquelas com base na iniciativa de psicanalistas individuais que se reuniram para esse fim, ou ainda com referência em serviços públicos de saúde mental. 


\section{ARTIGOS}

\section{Tentativa de elaboração preliminar da experiência até aqui obtida}

Com a inusitada situação de fato colocada pela pandemia de COVID-19 e com a rápida e vigorosa resposta da comunidade psicanalítica em participar efetivamente dos esforços no combate à crise sanitária, novos e desafiadores horizontes clínicos, teóricos e políticos foram colocados. A urgência e a gravidade da situação obrigaram a que "o tempo para compreender" fosse comprimido, a ponto de praticamente coincidir com "o momento de concluir". A premente necessidade de se criar um dispositivo clínico capaz de ser colocado em funcionamento imediatamente fez com que sua elaboração fosse baseada na pouca experiência até então acumulada com a prática psicanalítica apoiada em suportes virtuais e nos parâmetros metapsicológicos e éticos de que dispúnhamos até o momento, segundo as modalidades habituais de exercício da psicanálise.

Dessa forma, examinaremos a seguir, em uma primeira tentativa de elaboração um pouco mais à distância, alguns dos aspectos mais relevantes da proposta clínica que colocamos em prática, assim como suas possíveis consequências a longo termo, no contexto das lições a serem tiradas pela comunidade psicanalítica da experiência acumulada nesse período crítico.

Um primeiro parâmetro teórico-clínico que assumimos desde o início foi o de tentarmos explicitar para nós mesmos em quê o atendimento clínico que passaríamos a oferecer se especificaria do adjetivo "psicanalítico"? Por certo, inúmeros outros dispositivos de alto valor clínico para a situação foram colocados à disposição de profissionais de saúde na linha de frente do combate à pandemia, bem como aos doentes e a seus familiares, frequentemente enlutados e sem condições de sequer prestar os ritos funerários a seus entes queridos levados pela COVID-19. Na própria Unicamp, através de seu Departamento de Psiquiatria (ver neste mesmo número da RLPF o artigo de Clarissa Dantas e colaboradores), um importante dispositivo de acolhimento e de psicoterapia para profissionais, pacientes e familiares, além de grupos Balint para médicos, foi colocado em funcionamento, o qual, mesmo sem se definir pela psicanálise, certamente apoia-se em vários referenciais psicanalíticos em sua ação. Haveria, então, alguma especificidade no "atendimento psicanalítico" proposto por um grupo constituído essencialmente de psicanalistas voluntários oriundos de diversas escolas e orientações teóricas?

Em uma primeira impressão, os propósitos e dispositivos efetivamente colocados em operação apresentavam inúmeras zonas de intersecção: em 
uma e outra experiências, a ênfase deveria recair fundamentalmente no acolhimento, na disponibilidade de escuta, na atenção benfazeja e livremente flutuante. Para todos, incluídos os próprios psicanalistas, o momento era de crise, de incerteza e de ansiedade, e, como bem apontava Lacan em seu gráfico apresentado no seminário X (1962-63), a angústia é vizinha de porta do acting-out e da passagem ao ato, o que impõe ao analista, mas também ao terapeuta, a tarefa clínica primária de bem modular a intensidade desse afeto potencialmente disruptivo. Se seus níveis são muito baixos, o sujeito sequer chega a se colocar em questão. Se atinge uma intensidade transbordante, pode conduzir ao desespero e à atuação inconsequente. Dessa forma, essa função imediata de acolhimento, escuta e gestão dos montantes de angústia parecia ser uma exigência incontornável a qualquer prática que chamaremos de "psicológica", apenas como comodidade retórica, realizada diante de condições tão insólitas e perturbadoras.

Por outro lado, colocava-se para nós, como parâmetro ético mais especificamente psicanalítico, a postura clínica de não buscarmos reduzir por antecipação o mal-estar e o sofrimento do sujeito buscando nosso auxílio a uma concepção agora sim meramente "psicológica" de crise e de trauma. Não se tratava, por certo, de negar a dimensão potencialmente traumática da perturbadora situação que coletivamente atravessamos, mas em primeiro lugar, de deixar advir a modalidade singular pela qual cada um se encontra subjetivamente interpelado pela — ou simplesmente "na" — turbulência provocada pela pandemia. Acolhimento, sim. Mas sem com isso abafar a possibilidade da emergência dos conflitos, gozos e fantasias singulares e, talvez, há muito tempo soterrados no sujeito e finalmente mobilizados pela crise atual. Nesse sentido, a dimensão propriamente psicanalítica do dispositivo teria a ver também com a suposição de que os efeitos da pandemia sobre um sujeito específico podem não se resumir à sua potência de trauma subjetivo, mas também de resto diurno, capaz de dar vida e voz a demônios há muito silenciados naquela pessoa que agora busca ajuda.

Não decorre disso que o dispositivo psicanalítico criado para a situação emergencial tenha qualquer pretensão de instituir uma situação analítica capaz de levar um tratamento psicanalitico a suas últimas consequências. A própria duração limitada do tratamento proposto explicita de antemão o caráter correlativamente bem delimitado de seus objetivos. Trata-se, pois, fundamentalmente, de acolher aquele que nos busca mobilizado pelo contexto da pandemia, de modo a escutá-lo(a) na sua posição de sujeito singular, de pacificar os excessos transbordantes de angústia, de identificar os casos 


\section{ARTIGOS}

mais graves solicitando tratamentos especializados e de permitir a eventual interpelação do próprio paciente por si mesmo, em face do enigma de sua verdade subjetiva mobilizada pelo real desnudado pela crise sanitária. Essa é, por certo, uma condição indispensável para uma eventual entrada em análise, se esse for o caso, a ser realizada em outro contexto, mais específico para tal fim, sem quaisquer relações diretas com o dispositivo colocado em funcionamento em caráter emergencial.

Todas essas considerações, se apresentam de forma genérica as grandes diretrizes propriamente psicanalíticas da proposta clínica, ainda deixam de lado um aspecto fundamental ali colocadas em jogo: a questão do suporte tecnológico que tornou possível o tratamento e seu caráter eminentemente virtual. Vejamos, portanto, alguns elementos que nos pareceram fundamentais em uma primeira tentativa de recenseamento das questões éticas, teóricas, clínicas e políticas decorrentes dessa experiência.

\section{O virtual e os novos horizontes da clínica psicanalítica}

Uma primeira impressão generalizada - ainda sob o efeito do "calor da hora" da descoberta, apropriação e uso maciço de suportes tecnológicos tornando possíveis a realização de sessões virtuais de uma prática que se pretende psicanalítica - é a de que se trata de um instrumento técnico com imensas possibilidades e que, provavelmente, veio para ficar. Sob a ótica do risco de ficarmos à mercê de uma completa impotência no campo clínico durante o período de isolamento, os tratamentos mediatizados por dispositivos virtuais mostraram-se um recurso não apenas aliviante, mas positivamente útil e, sem dúvidas, promissor. Como todos outros momentos de desafio à clínica psicanalítica, este que agora atravessamos deve nos inspirar certas condições preliminares para estarmos em posição de com ele lidarmos de forma apropriada.

Em primeiro lugar, deve-se ter em mente que em psicanálise, como em qualquer outra modalidade clínica, a técnica deve estar a serviço da ética e somente nesta pode encontrar sua justificação. Correlativamente, naquilo que se refere de maneira mais específica à metapsicologia do tratamento psicanalítico, certas questões fundamentais deverão ser objeto de pesquisa e de elaboração no seio da comunidade dos psicanalistas. Entre elas podemos elencar, sem a pretensão de aqui tentar respondê-las: 
Qual o lugar das presenças concretas e dos corpos de analisante e analista na sessão analítica?

Que estatuto psicanalítico atribuir à noção de "virtual" quando esse conceito é extraído de seu contexto tecnológico para ser examinado segundo uma perspectiva especificamente metapsicológica?

Como situar os "terceiros" materializados nas figuras dos intermediários desse dispositivo clínico, tais como as grandes empresas de informática, de comunicação remota, de inteligência artificial e, até mesmo, os provedores de internet?

Que tipo de confidencialidade está em jogo em um dispositivo clínico diretamente apoiado em "pequenos outros" comerciais, jurídicos e políticos sobre os quais não se têm acesso ou controle?

$\mathrm{O}$ que pensar de propostas psicoterapêuticas e mesmo daquelas que se reclamam do significante "psicanálise" que propõem o desenvolvimento de tratamentos virtuais através de inteligência artificial de hiperperformance e, até mesmo, de avatares humanos virtualmente indistinguíveis de terapeutas humanos em tratamentos à distância? Como a psicanálise pode responder, desde uma perspectiva lógico-formal, ao problema levantado pelo próprio Alain Turing (1950), já no final dos anos 1940: sob que critérios seria possível distinguir uma máquina de inteligência artificial de altíssima sofisticação lógica e de imensa capacidade de processamento de um ser humano real?

Qual o papel da condição mortal de ambos os participantes concretos da situação analítica na instalação, atravessamento e final da cura?

Essas são apenas algumas das questões mais prementes suscitadas pela passiva utilização das tecnologias de comunicação virtual no contexto da clínica psicanalítica, como esforço de resposta às urgências colocadas pela pandemia. Uma longa lista certamente deve ainda ser composta, de modo a podermos estabelecer um primeiro panorama geral dos desafios teóricos, éticos e políticos aos quais a psicanálise terá de fazer face em um futuro próximo.

Do ponto de vista mais especificamente político, gostaríamos de destacar pelo menos um outro ponto que nos parece essencial. A proliferação das práticas ditas psicanalíticas realizadas com o suporte de tecnologias de comunicação virtual abrem novos e inusitados horizontes de relação da psicanálise com a sociedade e com a cultura. Se até agora os esforços por tornar o tratamento psicanalítico acessível às camadas financeiramente mais desprovidas da população passavam necessariamente pela mediação de serviços públicos ou privados de saúde mental, pelas universidades ou pelos esforços das próprias Escolas de Psicanálise, doravante abriu-se 


\section{ARTIGOS}

o caminho para uma prática mais direta, barata e acessível, ligando sem intermediários institucionais o suposto psicanalista e o eventual analisante. Bem aproveitada, essa nova situação pode tornar possível alguma forma de escuta e de intervenção psicanalítica a uma vasta camada da população que por limitações econômicas, geográficas ou políticas jamais teriam acesso a elas nas condições atuais. Contudo, e correlativamente, abrem-se as portas a todo o tipo de "análise selvagem", charlatanismo e de abusos em nome da psicanálise. Que tipo de postura deverão ter os psicanalistas e as Escolas de Psicanálise diante desse novo quadro?

\section{Considerações finais}

À guisa de conclusão, gostaríamos de sustentar a ideia de que a exposição súbita a esse "admirável mundo novo" das relações da psicanálise com as tecnologias de comunicação exigirá de todos um grande esforço de serena elaboração, de explicitação cada vez mais precisa das exigências éticas da clínica psicanalítica e a altivez do espírito, que Lacan identificou em Antígona ao ter que escolher sobre seu próprio destino: para além do medo e da piedade. De fato, essas novas condições constituem um desafio para psicanálise, mas também uma grandiosa oportunidade para que a disciplina criada por Freud renove seu encontro com seus próprios fundamentos, evitando - mais uma vez — o risco de se cristalizar como uma língua morta.

\section{Referências}

Ab'Sáber, T. E. M., \& Broide, E. E. (2017). Clínicas públicas de psicanálise. Lacuna: uma revista de psicanálise, 3,2. Recuperado em 20 jul. 2020, de: $<$ https:// revistalacuna.com/2017/04/28/n3-02/>.

Alves Lima, R. (2019). Clínicas públicas nos primórdios da psicanálise: uma introdução. Teoría y Crítica de la Psicología 12, 292-314. Recuperado em 18 jul. 2020, de: $<$ http://www.teocripsi.com/ojs/index.php/TCP/article/view/292>.

Caffé, M., Rocha, P. S., \& Pereira, M. E. C. (2007). Psicanálise e internet: uma combinação possível? Percurso. Revista de Psicanálise, 39, 141-148.

Coaracy, A., \& Guimarães, T. (2019). A experiência brasileira da psicanálise na rua. Teoría y Crítica de la Psicología, 12, 290-291. Recuperado em 18 jul. 2020, de: <http://www.teocripsi.com/ojs/index.php/TCP/article/view/288>. 
Danto, E. A. (2019). As clínicas públicas de Freud: psicanálise e justiça social. (Trad. Margarida Goldstajn). São Paulo, SP: Perspectiva.

Figueiredo, A. C. (1997). Vastas confusões e atendimentos imperfeitos: a clínica psicanalítica no ambulatório público. Rio de Janeiro, RJ: Relume-Dumará.

Lacan, J. (1997). O seminário. Livro 7. A ética da psicanálise. Rio de Janeiro, RJ: Jorge Zahar. (Trabalho publicado originalmente em 1959-60).

Lacan, J.(2005). O seminário. Livro 10. A angústia. Rio de Janeiro, RJ: Jorge Zahar. (Trabalho publicado originalmente em 1962-63).

Migone, P. (2013). Psychoanalysis on the internet: A discussion of its theoretical implications for both online and offline therapeutic technique. Psychoanalytic Psychology, 30(2), 281-299.

Oliveira, G. D. F. de, \& Ceccarelli, P. R. (2015). Realidade virtual v. realidade psíquica. Estud. psicanal. [online] 44, 101-107. Recuperado em 10 ago. 2020, de: $<$ http://pepsic.bvsalud.org/pdf/ep/n44/n44a11.pdf $>$.

Scharff, J. S. (2017). Psychoanalysis Online 3: The Teleanalytic Setting. London, UK: Routledge.

Turing, A. M. (1950). Computing Machinery and Intelligence. Mind, 49, 433-460.

\section{Resumos}

(Challenges posed to the psychoanalytic clinic (and its future) in the context of the COVID-19 pandemic: reflections from a clinical experience)

This article describes the implementation of a digitally supported psychoanalytical care service in the early context of the COVID-19 pandemic and the issues that arose from this experience, especially the role of the bodies and communication technologies at the start, during and at the end of the analysis.

Key words: Psychoanalytic clinic, online support, pandemic, COVID-19

(Les défis posés à la clinique psychanalytique (et son avenir) dans le contexte de la pandémie de COVID-19: réflexions à partir d'une expérience clinique)

Cet article présente la mise en place d'un service de soins psychanalytiques avec support virtuel dans le contexte naissant de la pandémie de COVID-19 et les enjeux qui en découlent, notamment le rôle des corps et des technologies de communication au début, pendant et à la fin de l'analyse.

Mots clés: Clinique psychanalytique, service en ligne, pandémie, COVID-19 


\section{ARTIGOS}

(Desafíos planteados a la clínica psicoanalítica (y su futuro) en el contexto de la pandemia de COVID-19: reflexiones desde una experiencia clínica)

El objetivo de este trabajo es presentar la implementación de un servicio de atención psicoanalítica con apoyo virtual en el contexto naciente de la pandemia de COVID-19 y las cuestiones derivadas de esta experiencia, especialmente, el papel de los cuerpos y de las tecnologías de la comunicación en la iniciación, continuidad y finalización del análisis.

Palabras clave: Clínica psicoanalítica, servicio en línea, pandemia, COVID-19.

Citação/Citation: Capoulade, F., \& Pereira, M. E. da C. (2020, setembro). Desafios colocados para a clínica psicanalítica (e seu futuro) no contexto da pandemia de COVID-19. Reflexões a partir de uma experiência clínica. Revista Latinoamericana de Psicopatologia Fundamental, 23(3), 534-548. http://dx.doi.org/10.1590/1415-4714.2020v23n3p534.6

Editora/Editor: Profa. Dra. Ana Maria G. R. Oda e Profa. Dra. Sonia Leite

Submetido/Submitted: 24.8.2020 / 8.24.2020 Aceito/Acepted: 24.8.2020 / 8.24.2020

Copyright: (C) 2009 Associação Universitária de Pesquisa em Psicopatologia Fundamental/ University Association for Research in Fundamental Psychopathology. Este é um artigo de livre acesso, que permite uso irrestrito, distribuição e reprodução em qualquer meio, desde que o autor e a fonte sejam citados / This is an open-access article, which permits unrestricted use, distribution, and reproduction in any medium, provided the original authors and sources are credited. 
Financiamento/Funding: Este trabalho não recebeu apoio / This work received no funding.

Conflito de interesses/Conflict of interest: Os autores declaram que não há conflito de interesses. / The authors declare that there is no conflict of interest.

\section{Francisco CAPOUlade}

Psicanalista; Doutor em Psicologia pela Universidade Federal de São Carlos e em Psychopathologie et Psychanalyse dans l'Université Sorbonne Paris Cité (Paris-Diderot); Bacharel em Filosofia pela Pontifícia Universidade Católica de Campinas e Mestre em Psicologia pela Pontifícia Universidade Católica de Campinas - PUC-Campinas (Campinas, SP, Br). Diretor do Instituto de Pesquisa e Estudos em Psicanálise nos Espaços Públicos (IPEP) (Campinas, SP, Br).

Rua Barbosa da Cunha, 17 - Jd. Guanabara

13073-320 Campinas, SP, Br.

franciscocapoulade@hotmail.com

https://orcid.org/0000-0001-6263-0161

\section{Mário Eduardo Costa Pereira}

Psiquiatra; Psicanalista; Professor titular de Psicopatologia Clínica pelo Laboratoire de Psychopathologie Clinique et Psychanalyse da Aix-Marseille Université (França); Livre-Docente em Psicopatologia do Departamento de Psicologia Médica e Psiquiatria da Faculdade de Ciências Médicas da Universidade Estadual de Campinas - Unicamp (Campinas, $\mathrm{SP}, \mathrm{Br}$ ), onde dirige o Laboratório de Psicopatologia: Sujeito e Singularidade (LaPSuS); Diretor do Núcleo de São Paulo do Corpo Freudiano - Escola de Psicanálise.

Rua Sampainho, 441/82 - Cambui

13025-300 Campinas, SP, Br.

pereiram@unicamp.br

http://orcid.org/0000-0002-7975-8863

This is an open-access article, which permits unrestricted use, distribution, and reproduction in any medium for non-commercial purposes provided the original authors and sources are credited. 